\title{
Finite Element Analysis for Verification Study of CFST Column under Vertical Loading
}

\author{
Payam Sarir ${ }^{*}$, Omid Monshi Toussi \\ PhD student, Department of Civil Engineering, School of Naval Architecture, Ocean and Civil Engineering, \\ Shanghai Jiao Tong University, Shanghai 200240, China \\ PhD student, Department of Civil and Environmental Engineering, Kassel University, Kurt-Wolters St 3, \\ Kassel, Hessen,34125, Germany.
}

\begin{abstract}
Concrete Filled Steel Tube (CFST) columns due to several benefits over the conventional composite columns are being more applicable in the constructions. The grade of composite connection between steel tube and concrete is one of the key factors in this structure. There are several experimental researches which were studied the composite action between steel tube and concrete and the different ways to increase the composition action; but few studies were performed numerical analysis for this matter. This study performed and used finite element (FE) to model and analyse a CFST column which was tested experimentally and attempted to verify the results for future evaluation. For this reason, different mesh sizes of $20 \mathrm{~mm}, 25 \mathrm{~mm}, 30 \mathrm{~mm}$ and $40 \mathrm{~mm}$ were analysed by using finite element software. The results were compared with the experimental test and indicated that the mesh size ES=20mm is a better match for this purpose and need to be considered for further analysis of this research.

Keywords: Concrete Filled Steel Tube (CFST); Column; Finite Element; Mesh; Concrete; Steel; Composite
\end{abstract}

\section{Introduction:}

Recently, the application of steel-concrete composites has been extensively increased in constructions. The concrete filled steel tube (CFST) columns have several benefits over the steel and reinforced concrete columns, such as; enhanced loading capacity and energy absorption, superior static and dynamic resistance and higher ductility which are due to improvement of composite grips between the steel section and the concrete (Han et al. 2008; Aslani et al. 2015; Sarir et al. 2016).Normally CFST columns in constructions are subjected to axial compression whether under full or partial compressive loading, such as: the bridge piers; arch structures or footbridges. One of the most applicable CFST columns in the constructions is the circular CFST (CCFST) column which is indicated in Figure 1 under axial loading (Han et al. 2008; Yang \& Han 2012; Yang et al. 2012).

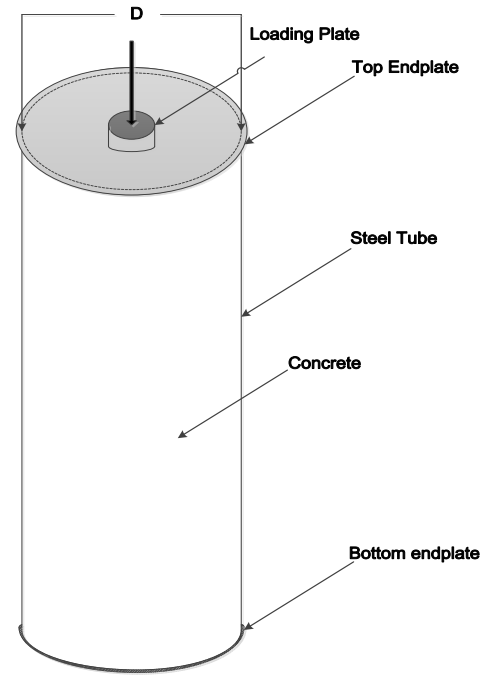

Fig. 1 Circular CFST Column under axial compression (Yang \& Han 2012)

There are varieties of research which were studied CFST subjected to partial or fully compression (Han et al. 2008; Yang\&Han 2009; Yang\&Han 2011). In addition, there are some studies were experimentally and numerically analysed the circular, square and rectangular CFST columns subjected to axial or eccentrically 
loading conditions. The results were indicated that there are effective differences of partial loaded CFST columns compared with the fully loaded columns (Bergmann et al. 1995).

This study attempted to numerically analyse the CFST circular column as indicated in Figure 1 by Yang \& Han in 2012 which is subjected to axial compression with length-to-diameter (L/D) ratio of 6. Developing the new techniques to analyse and evaluate the composite structures is always an engineering challenging (Sarir et al. 2016). For this reason, a numerical test using finite element (FE) software was performed to correlate the result of Yang \& Han (2011) study for further corresponding studies.

\section{Experimental test briefing}

A CFST column specimen as indicated in Figure 1 by Yang \& Han in 2012, with the length (L) of $900 \mathrm{~mm}$ and the diameter (D) of $150 \mathrm{~mm}$ and the wall thickness of $3 \mathrm{~mm}$ was performed in the laboratory. The length-to-diameter (L/D) ratio of specimen is 6 . The tubes were comprised of mild steel plate with $3 \mathrm{~mm}$ thickness and the yield stress, tensile strength, elastic modulus and Poisson's ratio of $324.4 \mathrm{Mpa}, 466.5 \mathrm{Mpa}$, $206,000 \mathrm{Mpa}$ and 0.281 , respectively. The concrete compressive strength applied in this test was $52.6 \mathrm{Mpa}$ and the elastic modulus was $33,600 \mathrm{Mpa}$.

The results implied the more ductility performance of the circular CFST column subjected to partially axial compressive loading. In addition, the modes of failure performance of the partially loaded CFST columns with $\mathrm{L} / \mathrm{D}=6$ were compared with the earlier results of previous studies with $\mathrm{L} / \mathrm{D}=3$. Results were showed that the length-to-diameter ratio does not have significant effects on the failure mode of the column.

\subsection{Introduction:}

\section{Numerical model assumptions}

This study applied LUSAS software for numerical analysis of the column test sample performed in the experimental study by Yang \& Han (2012). For this purpose in the first step, the model was created in the software for the analysis to obtain results for convergence purpose. In order to plot the model in LUSAS, the first step is geometry which the shape of model needs to be drawn. In the next step, meshing of the model has to be considered that making the model to perform structurally. The details of numerical model are explained in the following sections.

\subsection{Model Geometry:}

In the preliminary development of the FE model, the geometry of the specimens should be considered according to the details which are extracted from the reference paper by Yang \& Han (2012). That is important as the first step to verify the model by software. The geometry of steel tube and loading plate which are used in this study are indicated in Table 1 and 2.

Table 1. Steel Tube Section Geometry

\begin{tabular}{|lcc|}
\hline Length $(\mathrm{mm})$ & Diameter $(\mathrm{mm})$ & Thickness $(\mathrm{mm})$ \\
\hline 900 & 150 & 3 \\
\hline
\end{tabular}

Table 2. Loading Plate Geometry

\begin{tabular}{|cc|}
\hline Diameter $(\mathrm{mm})$ & Thickness $(\mathrm{mm})$ \\
\hline 150 & 12 \\
\hline
\end{tabular}

\subsection{Meshing:}

In this model to obtain an appropriate mesh for the analysis, a convergence test needs to be performed to reach the optimum mesh size. For this purpose four different mesh element sizes applied for both steel tube and concrete core and after analysis, the mesh size ES=20 $\mathrm{mm}$ reached the better match compared with element size $25 \mathrm{~mm}, 30 \mathrm{~mm}$ and $40 \mathrm{~mm}$.

\subsection{Element Type:}

There is a variety of element types in LUSAS software which each element can be assigned for specific structural members. The specification of each element is demonstrated in LUSAS manual reference. In this study three major elements are applied. The elements are utilized in this model are bar, interface and solid elements. For the solid element, a group of three dimensional isoparametric elements to model the boundaries is applied. Hexahedra (HX) have 20 nodes which each node carries 3 degree of freedom (DOF) (LUSAS Manual 2006).

\subsection{Material Properties:}

It is important in the LUSAS to assign appropriate material specifications to each element. In fact, each element structurally performs by assigning material properties. The combination of elements, meshes as well as 
materials behave as a complete structural model for analysis. For this purpose, material properties of applied steel tube specified in the Table 3 .

Table 3. Summary of Steel Properties

\begin{tabular}{|lc|}
\hline Properties & Value \\
\hline Young'sModulus & $206,000 \mathrm{MPa}$ \\
Poisson's Ratio & 0.281 \\
Mass Density & $5,600 \mathrm{Kg} / \mathrm{m}^{3}$ \\
Initial Yield Stress & $324.4 \mathrm{MPa}$ \\
Tensile Strength & $466.5 \mathrm{MPa}$ \\
\hline
\end{tabular}

Concrete is a material which has different performance in compression and tension. The concrete tensile strength is typically $8-15 \%$ of the compressive strength (Shah et al 1995). The material properties of concrete which is applied in this research is indicated in Table 4.

Table 4. Summary of Concrete Properties

\begin{tabular}{|lc|}
\hline Properties & Value \\
\hline Young'sModulus & $33,600 \mathrm{MPa}$ \\
Poisson's Ratio & 0.2 \\
Mass Density & $2,300 \mathrm{Kg} / \mathrm{m}^{3}$ \\
Compressive Strength & $52.6 \mathrm{MPa}$ \\
Tensile Strength & $1.5 \mathrm{MPa}$ \\
\hline
\end{tabular}

According to the previous studies, normally concrete failure is not likelihood due to only compression. In the compression test, the sample was loaded uniaxially which was caused tensile strains perpendicular to the loading direction. Due to poor performance of concrete in tension, cracks was occurred and expanded which caused failure of concrete at the end (Mindess and Young 1981; Shah et al 1995). In order to truly simulate the loading conditions in FE model, a loading plate is applied in the model to transfer loading through this object. The properties of the loading plate indicated in Table 5.

Table 5. Loading Plate Properties

\begin{tabular}{|lc|}
\hline Properties & Value \\
\hline Young'sModulus & $206,000 \mathrm{MPa}$ \\
Poisson's Ratio & 0.3 \\
\hline
\end{tabular}

\section{Analysis and discussion}

For FE analysis we have used LUSAS software and modelled the CFST column tested by Yang \& Han (2012). For this purpose the appropriate elements, meshes and materials were applied to simulate the column in experimental study. Figure 2 indicates the numerical model in LUSAS software.

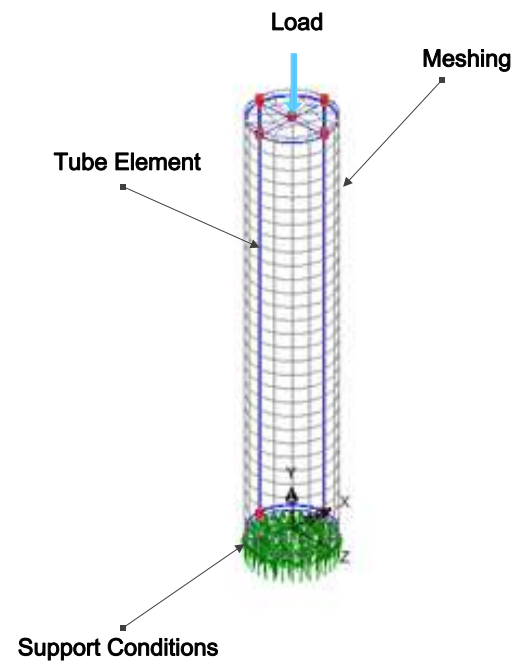

Fig2.Numerical model of CFST subjected to compression loading

In order to obtain the appropriate mesh size for the analysis, four models with different mesh sizes have been analysed and the results indicated in Figure 3. The results of each model compared with the experimental results. According to the results and comparisons, the mesh size of ES=20mm was the optimum mesh size for 
the analysis as the failure point of $1,350 \mathrm{kN}$ and corresponding deflections of 0.255 is in accordance with the experimental results by Yang \& Han (2012) as indicated in Figures 4. As evident, by considering mesh size of $\mathrm{ES}=20$ for FE analysis and assuming appropriate material properties, the results of experimental research and numerical analysis are in acceptance range and could be considered for the further analysis.

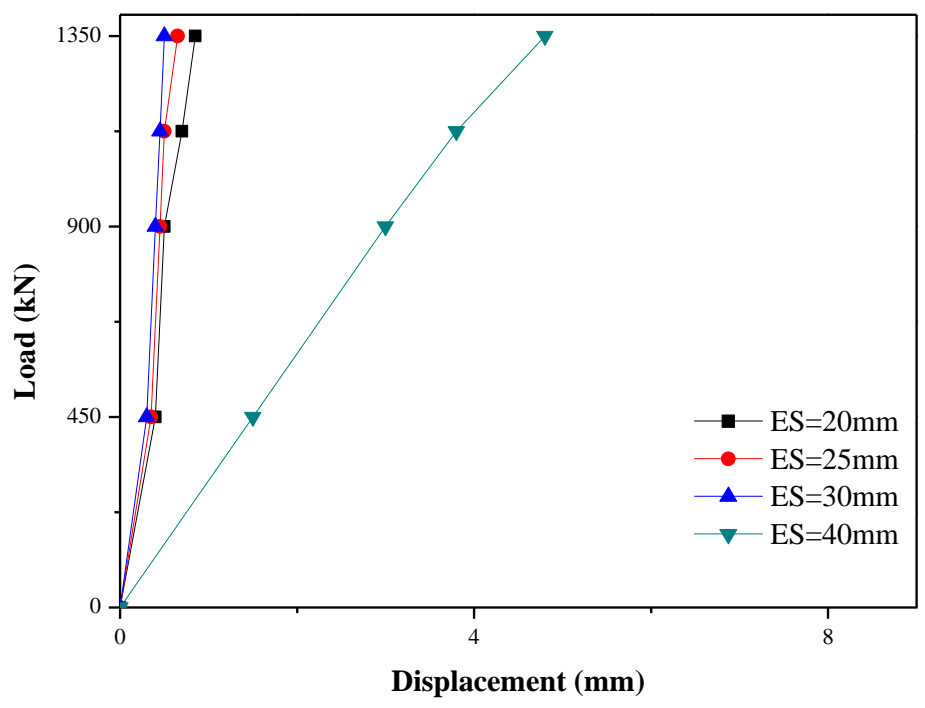

Fig3. Load-Displacement plot for various mesh sizes

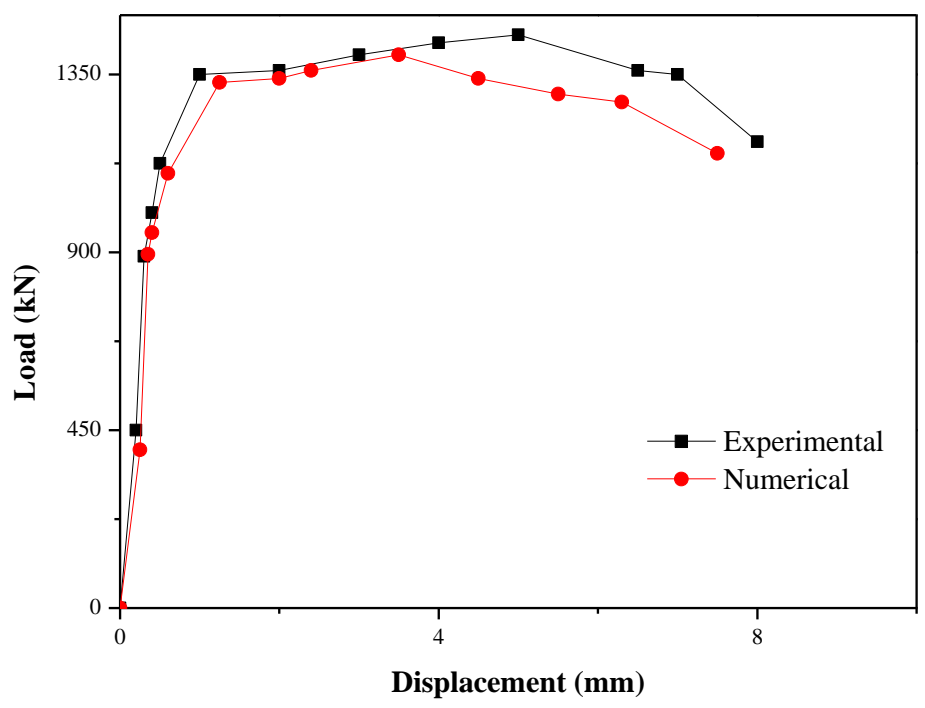

Fig 4.Experimental \& Numerical Load- Deflection Plot

\section{Acknowledgements}

The first author would like to express his appreciation to National University of Malaysia (UKM) on the permission use of software LUSAS Licensed, where the first author finished his Master Thesis from 2008 to 2010.

\section{References}

[1]. Aslani F., Uy B., Tao Z., Mashiri F. 2015. Behaviour and design of composite columns incorporating compact. Journal of Constructional Steel Research; Elsevier (107). 94-110.

[2]. Bergmann R., Matsui C., Meinsma C., Dutta D. CIDECT design guide for concrete filled hollow section columns under static and seismic loading. K oln: Verlag TUV Rheinland GmbH; 1995.

[3]. Chung C.H., Lee H.S., Park J.M., Kim Y.H. 2004. A New Perfobond Shear Connector of Composite Action. Journal of The Korean 
Society of Civil Engineers (KSCE). V 24. No. 3A. p 525-532

[4]. Han L.H., Liu W., Yang W.F. 2008. Behaviour of concrete-filled steel tubular stub columns subjected to axiallylocal compression. Journal of Constructional Steel Research, Elsevier. (64) 377-387.

[5]. LUSAS manual. 2006. Element reference manual. Version 14.3. Licensed of University Kebangsaan Malaysia.

[6]. Mindess, S. \&Young, J. F. 1981. Concrete; New Jersey: Prentice-Hall, Inc.

[7]. MonshiToussi, O \&Sarir, P. 2016. Finite Element Analysis of Composite Deck Slab Using PerfobondRib as Shear Connection System under Vertical Loading. Journal of Engineering Research and Applications. ISSN: 2248-9622, Vol. 6, Issue 1, (Part - 4) January 2016, pp.72-74.

[8]. Sarir, P., Shen, S.L.,Arularjah, A., Horpibulsuk, S. (2016). Concrete wedge and coarse sand coating shear connection system in GFRP concrete composite deck. Construction and Building Materials Journal, 114, 650-655.

[9]. Sarir, P\&MonshiToussi, O. 2012. Load-Deflection Behaviour of FRP Concrete Composite Deck. International Students' Conference of Civil Engineering, ISCCE 2012, 10-11 May 2012, Epoka University, Tirana, Albania

[10]. Shah, S. P., Swartz, S. E., \& Ouyang, C. 1995. Fracture Mechanics of Concrete. New York: John Wiley \& Sons, Inc.

[11]. Yang Y.F., Han L.H. 2012. Concrete filled steel tube (CFST) columns subjected to concentrically partial compression. Thin-Walled Structures Journal; Elsevier(50) 147-156.

[12]. Yang Y.F., Han L.H., Sun B. H. 2012. Experimental behaviour of partially loaded concrete filled double-skin steeltube (CFDST) sections. Journal of Constructional Steel Research 71 (2012) 63-73 